\title{
DESENCONTROS ENTRE ENSINAR E APRENDER FILOSOFIA
}

Filipe Ceppas ${ }^{1}$

RESUMO: Uma apresentação sumária de possíveis definições de ensinar $e$ aprender filosofia e seus desencontros, com ênfase nas ideias de transmissão, orientação, encenação e "falar em nome próprio".

PALAVRAS-CHAVE: ensino de filosofia, transmissão, aprendizagem, falar em nome próprio.

RESUMEN: Una presentación sumaria de posibles definiciones de enseñar y aprender filosofía, y de sus desencuentros, con énfasis en las ideas de transmisión, orientación, encenación y «hablar en nombre propio».

PALABRAS CLAVE: enseñanza de filosofía, transmisión, aprendizaje, hablar en nombre propio.

\section{Ensinar}

O professor, o único digno desse nome, o bom professor, segundo os alunos, seria aquele que sabe passar a matéria, aquele que passa bem a matéria. $\mathrm{O}$ professor, aquele que supostamente sabe como fazer e como fazer bem. A verdadeira transmissão do professor não é uma mera transmissão, é uma boa transmissão. Ele passa bem e ele passa bem alguma coisa, a matéria. Não é só esse "passar bem" que é misterioso na definição comum, mas também "a matéria". Há, sem dúvida, algo de material em ação na transmissão do professor: uma voz, os gestos, o corpo mesmo do emissor-professor e o do receptor-aluno, o quadro, o livro... Mas a matéria que o professor passa ou transmite não é, propriamente, matéria: são ideias, conteúdos, modos de resolver problemas, de falar apropriadamente, de como se deve ou não se deve falar sobre determinado assunto, modos de escrever, de pensar. O "conteúdo" de um curso não é nunca algo que cabe inteiramente num texto ou numa fala autônoma. Ele é também (e

\footnotetext{
${ }^{1}$ UFRJ FE / PPGF - filcepps@gmail.com

CEPPAS, Filipe. Desencontros entre ensinar e aprender filosofia. Revista Sul-Americana de Filosofia e Educação. Número 15, nov/2010-abr/2011, p. 44-54.
} 
talvez naquilo que ele tem de mais essencial) performativo. O que significa dizer que o professor o transmite?

Segundo o antigo dicionário da língua portuguesa, imprenso em Lisboa em 1849, de autoria de Eduardo de Faria, "transmitir" é definido, muito simplesmente, como "deixar passar além" ("o vidro e os corpos transparentes transmitem a luz"). Essa singela definição, colada que está à etimologia da palavra, ${ }^{2}$ reinando soberana no velho dicionário, ${ }^{3}$ diz que transmitir não é passar, mas deixar ultrapassar (deixar passar além). Todo o mistério do ensino pode ser explorado a partir dessa definição.

Há, na transmissão, uma travessia a ser percorrida, um trans, um mais além a ser alcançado, uma ultrapassagem. Em que direção segue essa ultrapassagem? É comum pensar que o professor deve ajudar os alunos a passarem de um "estado de não saber", relativo a determinado assunto, a um "saber", à "matéria". Pensamos a transmissão do saber como sendo um ir mais além do não saber. Mas, se traduzimos a expressão "transmissão do saber" de modo mais preciso, apenas substituindo "transmitir" por "deixar passar mais além", transmitir o saber é deixar passar mais além do saber ele mesmo, e não mais além do "não saber", ou da ignorância. Ensinar é sempre caminhar em direção a um desconhecido.

Essas ideias encontram eco na tradição da filosofia. Uma das virtudes atribuídas ao método socrático é a de mostrar que não sabemos verdadeiramente aquilo que acreditamos saber. Neste sentido, o bom professor é aquele que nos faria ir mais além de um "suposto saber", coincidindo com nossa definição inicial de transmissão. Também para Hannah Arendt, a transmissão da cultura às gerações mais novas, a preservação do velho mundo que aí está, se dá essencialmente em função da possibilidade do surgimento do novo. Este seria outro modo de pensar a transmissão como um ir mais além do saber. Por fim, Nietzsche toma a divisa de Emerson para ilustrar outra ideia próxima à da educação como sendo uma ultrapassagem do saber: "um homem nunca se eleva

2 " "Transmitir" deriva de transmittere, um composto do verbo latino mittere, cujo significado originário remete à ideia de "deixar ir", "lançar" e, a partir daí, "enviar". Por associação com a preposição trans, que indica "mais além", adquire o sentido de fazer chegar um conteúdo, basicamente lingüístico, a outro." (CASTELLO \& MÁRSICO, 2005, pp.39-40)

${ }^{3}$ Apenas sucedida pelos verbos enviar e participar: ordens ou despachos. 
mais alto senão quando desconhece para onde seu caminho poderia levá-lo" (Emerson, apud NIETZSCHE, 2003, p. 141).

É estranho pensar a transmissão como uma espécie de salto no escuro, um "deixar passar mais além do saber". Os alunos falam de passar a matéria, e nós somos forçados a traduzir isso, a partir de nossa definição inical, como "deixar passar mais além da matéria", isto é, fazer o aluno ultrapassar a matéria. Ultrapassar a matéria, elevar-se, superar obstáculos: um curso não vai bem, os alunos não aprendem. O professor deixa passar: ajuda a passar mais além. $\mathrm{O}$ professor deixa passar, ele mesmo não passa: são os alunos que vão além, "passam de ano" e ultrapassam o professor, uma vez que aprender não é repetir exatamente aquilo que o professor diz, ou fazer exatamente o que professor faz. $\mathrm{O}$ corpo docente em sua materialidade é o próprio obstáculo. Mas o corpo do professor é um corpo transparente, que deixa passar a luz. Todos conhecemos a falsa etimologia da palavra "aluno": o "sem-luz". Seguindo nossa definição, o aluno é, ao contrário, luz, e uma luz que ultrapassa o corpo transparente do professor, seu corpo de vidro. Às vezes o professor não está passando bem. Mas o professor que passa bem a matéria é o professor que deixa que o aluno o ultrapasse. O professor é um pouco suicida. ${ }^{4}$ Ele morre para que o aluno nasça, para que o aluno ultrapasse a matéria em direção ao que não é matéria. ${ }^{5}$

Mas por que deveríamos nos apegar a essa definição, mais originária, etimológica, de um velho dicionário? Os dicionários atuais, como o Houaiss, registram muitos outros sentidos para o verbete transmitir: conduzir e propagar (o metal transmite calor); emitir ou exalar (o jasmim transmite um agradável aroma); dar posse de algo a alguém (transmitir um cargo ou uma herança); fazer herdar algo que se tem (transmitir os gens ou o amor pela arte); destinar ou enviar (transmitir uma ordem ou uma mensagem); comunicar (transmitir uma notícia); fazer sentir (a sua presença me transmite calma), e, por fim, contagiar (transmitir

\footnotetext{
${ }^{4}$ Ver MERÇON, 2009.

${ }^{5} \mathrm{E}$ o que seria a morte do professor, a morte em geral, segundo as mais diversas tradições, sobretudo a platônica $e$ a cristã, senão uma ascenção $e$ libertação com relação à matéria, à "infecta carne humana", nas palavras de Sócrates, ao final do Banquete?
} 
uma doença). Muitos desses sentidos podem ser igualmente boas metáforas para o ensino como transmissão, em especial a propagação, o fazer sentir e o contagiar.

Não é raro pensar o ensino de filosofia no registro da propagação, do fazer sentir e do contágio. Se o tomamos como a transmissão de uma relação com o saber, mais do que de qualquer conteúdo específico, o professor é alguém que propaga uma certa atenção, uma certa postura investigativa, de modo semelhante ao metal transmitindo calor. O professor contagia o aluno. De Sócrates a Wittgenstein, a filosofia e sua transmissão são pensadas sob a forma de contágio, seja pela mania, pela intervenção de um daimon, seja mesmo como uma doença da qual devemos nos curar. E se a relação com o saber própria à filosofia é, por definição, uma relação fraterna, amorosa, neste sentido, transmitir a filosofia é também, necessariamente, fazer sentir. Não é nunca uma relação apenas intelectual, cognitiva.

Até aqui, estivemos apenas seguindo aquilo que os alunos dizem que é ensinar, a ideia do professor-transmissor: o professor que "sabe passar a matéria", que "passa bem a matéria". Mas a transmissão é ela mesma um sentido derivado de ensinar. Porque o sentido mais originário de ensinar é, antes, "colocar um signo de orientação":

"Ensinar" vem de insignare, literalmente "colocar um signo", "colocar um exemplo". A base do termo é a raiz indo-européia *sekw, cujo significado é "seguir", de modo que signum, o principal formador de insignare, remete ao sentido de "sinal", "signo", "marca" que é preciso seguir para alcançar algo. O "signo" é, então, "o que se segue", e "ensinar" é colocar sinais para que outros possam orientar-se (Castello \& Mársico, 2005, p. 37)

Os professores costumam sentir-se mais confortáveis aqui: nada de corpo de vidro, de luzes atravessando e misteriosas ultrapassagens. Aqui, ao contrário, o professor é um pouco como o guarda de trânsito. Sobretudo, nada de ultrapassagens perigosas! O professor dá signos, indica caminhos, controla o tráfego. Ponto final.

Mas "colocar um signo", "dar sinais", também não é algo assim tão protocolar. Quem está autorizado a dar sinais? O bom professor seria aquele capaz 
de orientar bem, sinalizar bem o caminho. Mas o que o bom professor, que ensina, sabe de sua arte de ensinar, de sua arte de dar sinais? Ao final do Ménon, Sócrates afirma que aquele que tem apenas uma opinião correta do caminho não é pior guia do aquele que tem ciência, que conhece o caminho. Num determinado momento, Sócrates sugere que a ciência não é mais do que o encadeamento de opiniões verdadeiras, que se consegue através da rememoração. Mas a opinião verdadeira não é, inicialmente, da ordem da ciência. Os homens bons, que administram corretamente a cidade, têm opiniões verdadeiras, mas não têm ciência, não as compreendem, eles não são "em nada diferentes, em relação ao compreender, dos pronunciadores de oráculos e dos advinhos inspirados" (99c). Por esta via, retomamos o sentido do contágio.

O Ménon é um diálogo centrado na questão da possibilidade de se ensinar a virtude. Trata-se de um diálogo aporético, de tal modo que não encontramos uma resposta definitiva à questão. Mas há uma conjectura que Sócrates não abandona, de que os homens bons não podem ser mestres da virtude, porque eles não possuem uma ciência. Ainda assim, tal como aquele que é capaz de guiar os outros corretamente pelo caminho a Larissa, tendo apenas uma opinião correta acerca deste caminho, mas sem conhecê-lo, sem nunca ter ido a Larissa, os homens bons parecem ser bons guias, porque agem de modo virtuoso e têm uma opinião correta acerca da virtude. Eles dão sinal. Mas Sócrates nega que eles possam ensinar a virtude. ${ }^{6}$

\footnotetext{
${ }^{6}$ Sócrates, no Ménon, avança a hipótese de que só seria possível ensinar a virtude caso esta fosse uma ciência (episteme). Mas, procurando responder à pergunta acerca da possibilidade de ensinar a virtude, ele perfaz um longo caminho para demonstrar que o seu conhecimento só seria possível caso admitíssimos que não sabemos o que é a virtude, que não temos essa ciência. "...acreditando que é preciso procurar as coisas que não se sabem, seríamos melhores, bem como mais corajosos e menos preguiçosos do que se acreditássemos que, as coisas que não conhecemos, nem é possível encontrar nem é preciso procurar..." (86b-c) Neste passo, Sócrates foge da aporia de Ménon, quando este diz que só poderíamos procurar conhecer algo que já conhecíamos. ("...de que modo procurarás, Sócrates, aquilo que não sabes absolutamente o que é? Pois procurarás propondo-te $<$ procurar $>$ que tipo de coisa, entre as coisas que não conheces? Ou, ainda que, no melhor dos casos, a encontres, como saberás que isto <que encontraste > é aquilo que não conhecias?" $80 \mathrm{~d}$ ). A passagem do escravo de Ménon demonstra que este já conhecia como calcular o dobro do quadrado, mas que não sabia que tinha esse saber. Ninguém ensinou nada ao escravo. E Sócrates tampouco o faz. Assim, se conhecemos a virtude, do mesmo modo que o escravo conhece o dobro do quadrado, ninguém será capaz de ensiná-la a nós. Podemos apenas nos colocar no movimento de conhecer-rememorar aquilo que sabemos, mas que não sabemos que sabemos. Mas esse saber ele mesmo não parece ser ensinável.
} 
Sócrates faz intervir a questão da verdade, da opinião verdadeira, na pergunta pela condição para ensinar a virtude, e, como vimos, ele mesmo relaciona aquele que possui uma opinião verdadeira aos oráculos e advinhos. Ensinar, neste caso, seria dar sinal, num sentido próximo às investigações de Heidegger à respeito da verdade, o desvelado. Ao contrário da ideia de ensinar como transmitir, como "deixar passar mais além do saber" ou "mais além da matéria", o caminho do desvelamento é, antes, uma imersão no saber e na matéria, na physis. Em Os conceitos fundamentais da metafísica, Heidegger apresenta o fragmento 93 de Heráclito ("O senhor [Anáx], cujo oráculo está em Delfos, não enuncia, nem esconde, mas dá um sinal") e afirma:

O que há de mais elevado em todas as coisas, de cujo homem é senhor, é dizer o desvelado, e, juntamente com isso, agir katá physis, isto é, inserir-se e apresentar-se na vigência total $e$ no destino do mundo em geral. (p.35)

Ensinar, dar sinais, neste sentido, é buscar a compreensão do homem como o ser-aí da natureza, da physis, que Heidegger traduz como vigência autoinstauradora do ente na totalidade; nada mais distante disso do que a imagem do professor como aquele que apenas bem orienta o caminho a seguir.

Há uma última concepção de ensinar que seria preciso apresentar aqui, contrapondo-a às outras quatro que acabamos de ver (deixar ultrapassar, contagiar, orientar, desvelar): ensinar pode ser, também, uma encenação, um compartilhar signos, um exercício simultâneo, também, de eventual propagação e contágio, mas sobretudo de criação e desconstrução. Ensinar pode ser abrir um diálogo livre com os saberes, com a tradição, o convite para um exercício de pensamento o mais livre possível de qualquer amarra institucional. Aqui, a figura do professor não é a daquele que professa, que proclama, e não tem como finalidade a ultrapassagem dos alunos, ou sua orientação, nem mesmo o desvelar do sentido do ser. Mais próximo à fábula, o ensino aqui é uma encenação coletiva, onde as funções de ator e plateia são a todo momento trocadas, não apenas entre professor e alunos, mas também entre o estudante e o estudado. 
Quando lemos um autor, por exemplo, partimos geralmente do princípio de que iremos entendê-lo segundo sua ordem das razões, isto é, que, após algum esforço, seremos capazes de julgar seus textos, encontrar suas lacunas e suas virtudes, reconhecer o que o autor quis dizer, ainda que ele não o tenha dito, etc. Sobretudo na tradição da história da filosofia e do comentário do texto, dominante entre nós, a filosofia é, em grande medida, essa arena em torno do juízo correto, por mais que sejamos modestos, céticos ou precavidos, e o professor é o guardião da chave desse juízo correto. Mais próximo à imagem de uma arte adivinhatória (sem nenhum compromisso programático com a verdade, seja entendida como correspondência, seja como o desvelado), o ensino como encenação poderia explorar, antes, a pergunta sobre como os textos nos compreendem; quais os signos que eles nos dão para nos lermos a nós mesmos e o mundo, um pouco como as cartas de um tarot.

\section{Aprender ${ }^{7}$}

Aprender filosofia. Como começar a pensar em tema tão genérico sem, por um lado, cair nos insuportáveis lugares comuns ou, por outro, fazer um mero inventário de idiossincrasias de um percurso pessoal? Na verdade, o principal lugar comum sobre o aprendizado da filosofia nos arremessa imediatamente no inventário pessoal: a ideia de que cada perspectiva filosófica engendra sua própria concepção do que seja aprender filosofia faz com que falar sobre o aprendizado da filosofia seja falar desde uma determinada perspectiva, com a qual nos identificamos: hermenêutica, analítica, frankfurtiana, deleuziana etc. Para tentarmos escapar a essa delimitação, via de regra recaímos em outros lugares comuns: não é possível senão aprender a filosofar, ou não se aprende filosofia na universidade. E acabamos convocando os autores para falar por nós, para dizer o impossível: aquilo que seria, para nós, o aprendizado da filosofia.

\footnotetext{
${ }^{7}$ Algo do que aqui se diz sobre aprender filosofia poderia ser posto em diálogo com (ou é em parte inspirado por) aquilo que Julio Cabrera desenvolve acerca da produção filosófica em nosso país, em seu livro Diário de um filósofo no Brasil (Cabrera, 2010).
} 
Não tenho nenhuma ideia grandiloquente relativa ao aprendizado da filosofia. Ou, melhor, tenho um quase nada, provavelmente decepcionante: aprendemos filosofia a cada filosofema sobre o qual nos debruçamos, a cada pensamento que cultivamos sobre a vida, as coisas, o ser, o não-ser, a morte, etc, independente de perspectivas, critérios e parâmetros comumente identificados com "a filosofia". "O professor" pode dizer que isso não basta, que a filosofia exige rigor; que a filosofia isso e a filosofia aquilo; que um pensamento só não faz verão. Pode ser. Mas, francamente, isso não me interessa. No que ela tem de melhor, a filosofia é, sobretudo, uma atenção, um exercício que se dá a cada um segundo o acaso de seus encontros, com um pensamento, um livro, um amor. É um exercício variável, que gira em torno da verdade como um incessante jogo de velamento $e$ desvelamento, e de resistência a uma vida que nos amesquinha. E o próprio jogo da filosofia às vezes nos amesquinha, como Nietzsche e outros não cansaram de denunciar.

Esse quase nada já é muita coisa. Não sei se sou capaz de dizer muito mais do que isso sobre essa questão tão difícil: girar em torno da verdade, resistir à cretinização geral da vida. Seria mais fácil se nos apoiássemos diretamente em um autor, em um pensador: Heráclito, Sócrates, Descartes, Rousseau, Foucault, Quine, qualquer um... Deixá-los falar e, como é de praxe, pontuar essas falas com o intuito de aprender alguma coisa. Mas aprender filosofia talvez seja também, e sobretudo, aprender a "falar em nome próprio" e isso, de fato, nós não aprendemos a fazer: enfrentar a verdade desarmados, despojados da erudição. Impossível despojar-se totalmente, é claro. Nesta rápida e superficial caracterização do que seja, para mim, aprender filosofia, por exemplo, não consegui deixar de fazer referências a Heidegger e a Foucault. E o que eu sei de Heidegger? Pouco, muito pouco. E, ainda assim, não imagino ser possível pensar o conceito de verdade sem levar em conta a ideia de um jogo de velamento e desvelamento. $\mathrm{O}$ que eu sei de Foucault? Pouco, muito pouco. Mas, ainda assim, parece impossível deixar de pensar que esse enfrentamento da verdade é um exercício de resistência, de compreensão das formas de subjetivação que nos constituem e nos assujeitam. Etc. Aprender filosofia não tem como finalidade saber repetir o que se sabe e o que 
não se sabe, nem mesmo saber, enfim, "apresentar uma questão original", mas estar alerta, atento, capaz de avançar o pensamento uma vez que uma questão esteja posta. ${ }^{8}$

A questão que nos propusemos trabalhar, aqui, foi a dos desencontros entre ensinar e aprender filosofia e para isso foi preciso qualificar, de algum modo, ensinar e aprender filosofia. Consideremos, agora, brevemente, essa ideia de que aprender filosofia é, naquilo que ela tem de mais essencial, aprender a falar em nome próprio, girando em torno da verdade e resistindo ao que nos amesquinha. « Mas que definição mais iluminista! » poder-se-ia retrucar: «O que é "falar em nome próprio"? Como, depois de ler Derrida, por exemplo, sustentar uma ideia tão problemática? E o que significa "girar em torno da verdade"? E o que você quer dizer quando afirma que a vida nos amesquinha? » Já vemos onde esse quase nada nos leva.

Sem dúvida, o nome próprio, a noção mesma de propriedade é um conceito antinômico. Um nome é sempre dado por alguém, nunca é próprio. Ou, segundo Lévi-Strauss, "nunca se dá um nome: classifica-se o outro... ou classificase a si mesmo" (Pensamento Selvagem, apud DERRIDA, 1973, p. 135). Como ressaltou Derrida na Gramatologia, apesar de ter formulado esse princípio fundamental para a antropologia, Lévi-Strauss acaba por ignorá-lo em sua análise dos Nhambiquaras, em Tristes Trópicos, ao sugerir que a proibição, que os índios se impõem com extremo rigor, de revelar seus nomes próprios ao antropólogo, fornecendo a ele apenas apelidos ou "nomes fantasias", é uma estratégia de preservação de uma inocência original, mais próxima à natureza e distante da banalização dos signos, comum às sociedades com escrita.

A crítica a Lévi-Strauss, na Gramatologia, gira em torno da ideia de que a escrita, para o antropólogo, é um instrumento de dominação, perigoso, responsável, nas civilizações ocidentais, pelo apagamento daquilo que seria próprio do humano - que seria, paradoxalmente, uma certa bondade (Rousseau) que o homem comparte com os animais (a piedade), e que encontrar-se-ia ainda em

\footnotetext{
${ }^{8}$ Essa seria uma concepção "desconstrutiva" de aprender filosofia, que põe em questão não apenas suas pretensões grandiloquentes, mas também a própria "filosofia" como um campo fechado, saber sistemático e "mãe" ou "rainha" das ciências.
} 
estado relativamente puro nas sociedades sem escrita - Segundo Derrida, sob pretexto de crítica ao etnocentrismo, Lévi-Strauss pratica um etnocentrismo às avessas, pressupondo a pureza do próprio, uma essência humana que é, afinal, a projeção de um esquema conceitual metafísico sobre o perspectivismo do povos ameríndios.

Supor que a escrita, a disseminação "anônima" de obras e ideias, apaga o nome próprio é apenas o reverso de supor que falar em nome próprio significa apagar aquilo que aprendemos com outrem, dando lugar a uma fala mais original. "Falar em nome próprio", a originalidade, a genialidade ou a autonomia do pensamento são mitos de um aprendizado da filosofia que sacraliza o texto dos pensadores como acesso a um significado transcendente, de difícil acesso, impedindo, paradoxalmente, que o estudante possa ensaiar ter um pensamento próprio. Portanto, quando penso, aqui, no aprendizado da filosofia como um "aprender a falar em nome próprio", não penso em nenhuma pureza ou originalidade, em nenhuma proibição de falar a partir da tradição, a partir do que outros já disseram.

\section{Desencontros}

A ultrapassagem, o salto no escuro, a propagação, o contágio e o desvelamento, ainda que fosse necessário pensar mais cuidadosamente sobre suas diversas implicações e contraindicações, são imagens interessantes para se conceber um ensino e um aprendizado da filosofia sob os signos da encenação $e$ da disseminação, da busca de uma voz que é própria, mas que não se quer pura, nem refém de um significado transcendente, por si mesmo engendrado ou estabelecido a priori. Contudo, o ensino de filosofia raramente abandona o princípio da orientação, da orthotés. E, tal como este é majoritariamente praticado entre nós, seria ainda mais difícil conceber um exercício de aprendizagem autoral de filosofia a partir daquela proposta mais radical de uma encenação coletiva, de um teatro filosófico a várias vozes e sem nenhum maestro. 


\section{REFERÊNCIAS BIBLIOGRÁFICAS}

CABRERA, Julio. Diário de um filósofo no Brasil. Ijuí: Ed. Unijuí, 2010.

CASTEllO, Luis A.; MÁRSICO, Claudia T. Oculto nas palavras. Dicionário etimológico para ensinar e aprender, Belo Horizonte, Autêntica. Trad. Ingrid M. Xavier, 2005, pp.39-40

DERRIDA, Jacques. Gramatologia, São Paulo: Perspectiva. Trad. Renato Janine Ribeiro, 1973.

HEIDEGGER, Martin. Os conceitos fundamentais da metafísica. Mundo, finitude, solidão. Rio de Janeiro: Forense Universitária. Trad. Marcos Casanova, 2003.

MERÇON, Juliana. "A sonhada educação suicida: notas spinozanas sobre o pensar e o educar", in: CEPPAS, Filipe et. al. (orgs.) Ensino de Filosofia. Formação e emancipação. Campinas: Alínea, 2009, pp.119-130.

NIETZSCHE, Friedrich. "Schopenhauer como educador", In: Escritos dobre educação, Rio de Janeiro: PUC/Edições Loyola. Trad. Noéli C. de M. Sobrinho, 2003.

PLATÃO. Ménon. Rio de Janeiro: PUC/Edições Loyola. Trad. Maura Iglésias, 2001.

Recebido em 13/10/2010.

Aprovado em 21/01/2011. 